\title{
Membrane Distillation heat transfer enhancement by CFD analysis of internal module geometry
}

\author{
A. Cipollina, G. Micale, L. Rizzuti \\ Dipartimento di Ingegneria Chimica dei Processi e dei Materiali, Università degli Studi di \\ Palermo, viale delle Scienze Ed.6, 90128-Palermo (ITALY). E-mail: \\ cipollina@dicpm.unipa.it
}

\begin{abstract}
Module geometry optimisation can be a crucial matter in all separation processes using selective or hydrophobic membranes, e.g. Reverse Osmosis (RO), Membrane Distillation (MD). In fact the choice of suitable channel shape and size can dramatically affect the performance of the process. With reference to the membrane distillation process, temperature polarization phenomena and pressure drops along the channels largely affect the process efficiency (i.e. the efficient use of temperature driving force for the passage of vapour through the membrane) as well as pressure distribution, module mechanical resistance and pumping costs.

Several works have been presented so far in literature on the fluid flow characterization of spacer-filled channels for the case of Reverse Osmosis modules, but only few works deal with the problem of MD modules optimization.

The present work aims at the CFD simulation of the fluid flow and temperature fields within spacer-filled MD module channels for a variety of spacer geometries. Both commercial and custom made geometries have been simulated in order to identify the most important parameters affecting process efficiency. The commercial CFD code ANSYS CFX11.0 has been adopted to perform simulations.

Results provide valuable information to identify the main features which an optimised spacer should possess in order to minimise T-polarization and pressure drops along the channel.
\end{abstract}

Keywords: Computational Fluid Dynamics, Membrane Distillation, spacer geometry, design optimisation, simulation, temperature polarization 


\section{Introduction}

Among the variety of membrane desalination processes, Membrane Distillation (MD) is one of the most emerging and interesting. It is an hybrid process combining the advantages of thermal and membrane desalination processes. The physical principle for the separation is based on the use of a hydrophobic membrane, which effectively separates water vapour from any salt solution, thanks to a driving force related to the difference in vapour partial pressure at the two sides of the membrane. Such a difference is related to the temperature of the hot feed and to the temperature and configuration of the cold distillate channel. In fact, the vapour after passing through the membrane can then be condensed in different ways according to several different process configurations, as detailed in the following paragraphs.

Though still being a niche technology, in the last two decades membrane distillation gained room upon conventional separation processes. This is mainly due to the following advantages $[1,2]:$

- Low sensibility to fouling and scaling;

- No corrosion problems;

- $100 \%$ theoretical salt rejection;

- Low electrical energy consumption during the operation;

- Compactness and modularity of the unit;

- Easiness of conduction, control and maintenance of the unit;

- Lower operative pressure than conventional membrane processes;

- Reduced vapour spaces compared to conventional distillation processes;

- Suitability for coupling with renewable energy and waste heat sources;

Despite all these advantages, membrane distillation for seawater desalination is not implemented yet on industrial scale, due to the following reasons:

- Relatively low permeate flux compared to other separation techniques such as reverse osmosis;

- Membrane and module design still optimised for other processes;

- Relatively high thermal energy consumption; 
In general these drawbacks are likely to be solved in the next years thanks to the numerous efforts and research projects focused on the development of this technology.

Presently, the start of the art of MD technology presents already four possible MD configurations:

1) Direct contact membrane distillation (DCMD), where the condensing fluid is in direct contact with the membrane

2) Air gap membrane distillation (AGMD), where the condensing surface is separated from the membrane surface by an air gap

3) Sweeping gas membrane distillation (SGMD), where a cold inert gas carries the vapour in an external condenser.

4) Vacuum membrane distillation (VMD), where vacuum is applied on permeate side by a vacuum pump, and the vapour is condensed outside in an external condenser

The sketch of possible configurations is represented in the following figure 1:

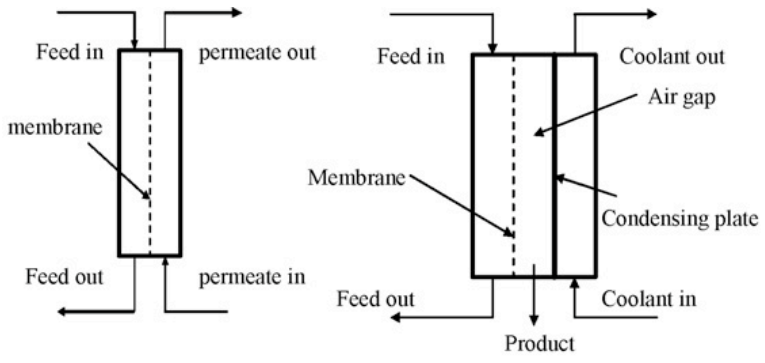

DCMD Configuration

AGMD Configuration

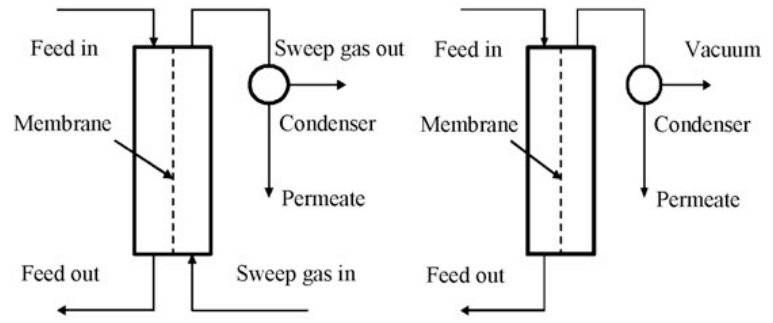

SGMD Configuration

VMD Configuration

Figure1 - MD process configurations

Among these possibilities, within the present research effort only the DCMD configuration is investigated, as this technology is the one presently developed within the EU project MEDIRAS, under which the present work has been carried out.

Several different geometries have been developed for MD modules. Among these, flat sheet, spiral wound and tubular are the most commonly adopted. In particular for the first two types, spacer and channel optimization requires careful analysis of the fluid flow and temperature fields in the channel.

Flow field analysis is necessary for the minimization of pressure drop along the channel. In fact, this parameter dramatically influences the pumping power requirements but also the pressure values inside the MD module itself. Operating pressure in the evaporating channel 
can not be too high, otherwise it will exceed the bubble pressure limit, which is the pressure at which droplets of the salty solution pass through the hydrophobic membrane, thus affecting the salt rejection of the separation process.

On the other side, the analysis of temperature fields is useful for the minimisation of temperature polarization along the vapour flux direction. The temperature polarisation phenomenon (which will be better described in the next paragraphs) is related to the presence in the evaporation channel (also in the condensation channel in DCMD configuration) of a temperature gradient between the hot liquid bulk and the liquid in contact with the membrane surface. Such gradient guarantees the heat transfer from the bulk to the membrane surface thus providing the heat required for the evaporation, but, on the other side, it reduces the effective driving force for the passage of vapour through the membrane, thus reducing vapour fluxes and process efficiency.

Due to the geometrical complexity of MD modules and to the difficulties of experimentally characterise fluid flow and temperature fields in real MD modules, Computational Fluid Dynamics can be an useful tool for geometry analysis and optimisation, providing extensive and detailed information on how channel and spacer geometry can affect velocity, pressure and temperature distribution inside the module.

In the present work CFD simulations of the fluid flow and temperature fields inside a spacer filled channel were performed in order to highlight possible keys for spacer optimisation with the final aim of enhancing the performances of MD modules.

\section{CFD modelling of spacer-filled channels}

The open literature reports a number of works focused on the characterisation and optimization of fluid dynamics inside the channel of membrane modules through the use of CFD tools. Here a short review of such studies is reported with the aim of presenting the most advanced findings on this matter. It is worth noting, however, that most of these studies are focused on the analysis of pressure driven membrane processes (RO, UF, etc.), while very little information is available on temperature driven processes like MD.

One of the first studies on the fluid dynamics in spacer filled channel was presented by $\mathrm{Da}$ Costa et al. in 1991 [3] through an experimental study, reporting on pressure losses and concentration polarization for six different commercial spacers tested in a laboratory test cell. Their results actually indicated the best geometry among the six tested, but did not give 
general information on the effects that spacers can have on the fluid dynamics inside the channel and were limited to the experimentally studied geometries.

In 1994, the same authors [4] presented a second work concerning the development of a simplified semi-empirical model. It allowed the visualization of a peculiar fluid dynamics behaviour generated by the filaments. In fact, they noted a hybrid flow regime, which presented some features typical of laminar flow together with stationary vortexes close to the filaments. Though the developed model was found in good agreement with experimental data, no attempt was made to further analysing and modelling the interesting fluid dynamics features of the flow, and the model semi-empirical origin limited its validity to the sole geometries investigated.

In 2001, Karode and Kumar [5] proposed an interesting modelling work, based on Computational Fluid Dynamics codes, for the simulation of a lab-scale rectangular channel containing different types of commercial spacers, used by Da Costa et al. in 1994 [4]. However, results only concerned fluid dynamics aspects and no mention was made of the polarization phenomena. Moreover, the little computing potentials available at that time forced the authors to simulate only a portion of the channel imposing periodic conditions in all lateral boundaries, although this condition is not always acceptable even with systems with geometrical periodicity. However, an interesting finding of this study is related to the effect of asymmetrical geometries on the pressure drops and shear stress on the membrane surface. In fact, the authors show how symmetrical spacers ("diamond spacer") generate very similar fluid dynamics conditions on the two sides of the channel (i.e. on the two membrane surfaces), whereas asymmetrical spacers (for example those with different wire diameters or those with a flow parallel layer of filaments coupled to a layer crossing the flow) presents a strongly asymmetrical behaviour with high shear stress on the side of parallel filaments and generally lower pressure drops. Finally, they also observed how the fluid flow is not characterised by a zigzag path between filaments, but the fluid flows in each layer parallel to the main direction of filaments, inverting the direction only when it encounters the lateral wall, being thus force to pass to the other layer of filaments and change direction of flow.

In 2001 Cao et al. [6], presented a work focused on the fundamentals of fluid dynamics around cross filaments in different positions within a narrow channel. Observing that wall shear stress on the membrane surface reduces the boundary layer, enhancing the solute mass transfer, they highlighted the importance of finding an optimal distance between cross filaments, positioned alternatively on the two sides of the channel and deviating the flow towards the other side, thus increasing velocities on the membrane surface in this zone. This 
optimal distance should increase shear stress on the membrane surface, without increasing too much pressure drops. Interestingly, they also found how a central "suspended" filament, deviating the flow towards the two membrane surfaces (channel walls), gives a good compromise between enhanced and symmetrical shear stress on the membrane surface with reduced pressure drops and lack of calm zones behind each filament.

In 2002 Schwinge et al. [7] studied the transition from laminar flow regime to transitional regime, using 2D CFD simulations of simple geometries characterised by a channel filled with cylinders variously positioned. In particular the geometries were: 1) single filament adjacent to the wall; 2) single cylinder centered in the channel; 3) multiple cylinders adjacent to the wall and 4) zig-zag spacer (cylinders positioned alternatively adjacent to the upper and lower wall).

For all configurations there are complex relationships between the number, position and distance between the filaments, the diameter of the filaments, the Reynolds number and the eddy generation. Interestingly, authors noted that the transition from laminar to slightly unsteady flow occurred for lower values of Reynolds number than in the case of an empty channel. In particular the critical Reynolds, at which the first unsteadiness appears, are of 200, 300 and 400 for the centered, wall adjacent and zig-zag filaments spacers respectively.

In 2005, Dendukuri et al. [8] tested the effect of changing the shape of filament cross sections in commercial spacers, through a simplified CFD approach. Though results indicated some minor improvements in fluid dynamic performances (10-20\% reduction of pressure losses), the interest was limited to the fluid dynamics of the system, while no description of polarisation phenomena was done.

An other study, focused on the influence of the spacer geometrical parameters, like filaments distance and angle between filaments and main flow direction, on the flow field characteristics, was performed by Li et al. in 2004 [9].

Simulations results have shown how the decrease of $1 / \mathrm{h}$ ratio (ratio between the inter-filament distance and channel height) generates a decrease in the vorticity and consequently in the mass transfer rates. At the contrary, if the $1 / \mathrm{h}$ ratio is very high $(>10)$ eddies promoting the mixing will be limited to a small zone close to filaments, also generating low overall mass transfer rates. In particular the authors indicated as a good $1 / \mathrm{h}$ ratio for diamond shaped spacers the value of 4 .

More recently, Ranade and Kumar [10] performed RANS simulations (using the standard k- $\varepsilon$ turbulence model) in order to analyse the effects of channel curvature due to the spiral wound configuration of several types of membrane modules. Their results showed that no significant 
difference with flat channels is found for common curvature radius. Although the work presents some uncertainties, it gives an indication on the fact that planar geometry can be adopted to perform fluid dynamics analysis for spiral wound systems.

A CFD analysis focused also on the study of polarisation phenomena was published by Santos et al. in 2007 [11]. The work was limited to the case of concentration polarisation in a Reverse Osmosis test cell. They used an open source CFD code. Geometry was very simplified and the spacer constituted only by orthogonal filament with square cross section. Thus a simple structured grid was implemented in the calculus domain, but such an approach is quite far from being able to describe real spacer geometries, thus making results of minor interest. However, it is worth mentioning that shear stress and Sherwood numbers were found interdependent, thus confirming a relationship between mass and momentum transport phenomena.

Also in 2007, Koutsou et al. [12] presented a novel modelling approach, adopting more powerful computing hardware and modern commercial CFD codes, with the possibility of modelling the fluid dynamics of complex geometries using Direct Numerical Simulations (DNS) with high-resolution computational grids. In this case the study is limited to fluid dynamics aspects, analysing in particular the dependences of pressure losses with the two main geometrical parameters characterising diamond spacers, i.e. the distance between filaments and the attack angle. Results show that pressure losses decrease with the increase of the sistance and the reduction of the attack angle (i.e. least pressure losses with all longitudinal filaments). Model results were also validated with experimental data, collected using a test cell purposely built, but also in this case only pressure losses were measured. A later work by the same authors [13] extended the analysis to the concentration polarisation phenomenon and to the mass transfer rates. The authors analyse through a comprehensive study the influence of geometrical parameters and Schmidt number on shear stress, Sherwood number and, thus, mass transfer coefficients. Results, partially validated by purposely collected experimental data, indicate how both shear stress and Sh are maximised where transversal filaments deviate the flow towards to membrane surface, while the empty zones between filaments or the zones behind them are generally characterised by low values of these parameters. Moreover, the authors present original correlations relating Sh to $\mathrm{Re}$ and Sc for the different geometries considered, being somewhat in agreement with literature information. In general it is worth mentioning that, the above reported literature is predominantly focused on the study of the fluid dynamics of spacers and in some cases the problem of concentration polarisation and mass transfer has been taken into account. On the other side, concerning the 
problem of temperature polarisation, typical of Membrane Distillation (MD), relevant literature reports only preliminary studies on the thermo-fluid dynamics of MD systems. A very important paper was published by Schofield et al. in 1987 [14], in which for the first time the authors underlined the importance of thermo fluid dynamics analysis in MD channels and temperature polarisation minimisation. Indeed some very well focused experiments were presented in this work in which it was already highlighted the influence that geometrical parameters such as flow cross section and channel's characteristic length could have on the formation of T-polarisation, showing in particular how, even at low Reynolds numbers, small channel equivalent diameters could reduce dramatically polarisation, thus without significantly enhancing pressure drops and energy losses. CFD tools have been adopted by Cipollina et al. to simulate the thermo fluid dynamic inside spacer filled channels [15] or, by $\mathrm{Xu}$ et al., in tubular MD channels [16], finding in both cases that higher velocities reduce temperature polarisation by enhancing the heat transfer coefficients. In particular the former study underlined how in asymmetrical spacers, temperature polarisation is increased by transversal filaments, which create calm zones behind them. On the other side, Xu et al, focused jut on the influence of the Reynolds number, highlighting how any increase in Re, leads to important enhancement in the flux, by reducing temperature polarisation.

Another work, published by Alklaibi and Lior in 2007 [17], dealt with the analysis of the influence of cylindrical obstacles (simulating a spacer) in a rectangular MD channel by means of a 2D modelling. Looking at three different geometrical dispositions of the cylinders (zigzag, central suspended and non-central suspended), the authors found that the presence of central suspended cylinders significantly enhances the spacer efficiency (by reducing the temperature polarisation), whereas zig-zag spacers, with cylinders positioned in contact with the membrane do not perform so well.

Finally, other few works [18 - 21] present experimental studies mainly focused on the entire module performance characterisation, in some cases aiming at the optimisation of process performance by flux enhancement and temperature polarisation reduction [21], but without investigating in depth the fundamental aspect relevant to the thermo-fluid dynamics.

In the present work CFD simulations of the fluid flow and temperature fields inside a spacer filled channel were performed in order to highlight possible keys for spacer optimisation with the final aim of enhancing the performances of MD modules. Simulated geometries refer to the evaporation channel only. Nine different spacer geometries were assembled and simulated to analyse their impact on pressure drops and T-polarisation within the channel. As suggested 
in the above reviewed literature, custom spacer geometries were purposely assembled in order to have a symmetrical disposition of filaments, beneficial for a correct operation of symmetrical module channels [5], with a central layer of transversal filaments which enhance turbulence and mixing [6], leaving longitudinal spacers on the membrane surface to keep high velocities and low pressure drops along the channel. In particular, this choice was also supported by previous authors' findings that have been recently published [15]. 


\section{Transport phenomena and Temperature polarization in Membrane}

\section{Distillation}

Modelling the fluid flow and temperature fields of MD channels requires the knowledge of mass and heat transport phenomena in the system.

The mass flux is related to the vapour passing through the membrane, regulated by three diffusion mechanisms [14]:

1) Knudsen diffusion through the membrane pores;

2) Poiseuille flow through the membrane microchannels (formed to interconnected micropores);

3) molecular diffusion through the air trapped inside the pores.

For the sake of brevity only the final overall expression for the mass flux is reported:

$$
N_{v}=C \cdot\left(P_{1}-P_{2}\right)
$$

where $C$ is to be regarded as a permeability coefficient of the membrane (slightly dependent on the temperature). If convective mass transfer is predominant, $\boldsymbol{C}$ will be strongly dependent on the geometry of the pores; if diffusive mass transfer is predominant, $\boldsymbol{C}$ will be strongly dependent on the average molar fraction of air in the pores.

$\left(\mathrm{P}_{1}-\mathrm{P}_{2}\right)$ is the vapour partial pressure difference at the two sides of the membrane. Considering the equilibrium relationship between temperature and vapour pressure, and neglecting the effects of salts on such equilibrium eq. 1 can be then rewritten as:

$$
N_{v}=\left.C \cdot \frac{d P}{d T}\right|_{T_{m}} \cdot\left(T_{1}-T_{2}\right)=C_{T_{m}}^{\prime} \cdot\left(T_{1}-T_{2}\right)
$$

where $\left.\frac{d P}{d T}\right|_{T_{m}}$ is the slope of the vapour-liquid equilibrium curve at an average temperature $T_{m}$ and $C^{\prime} T m$ a new mass transfer coefficient, which can be considered constant for small ranges of operating pressures, where $\frac{d P}{d T}$ can be considered constant. 
The heat flux is related to the passage of heat from the hot liquid to the cold permeate (assuming for example a direct contact configuration), and is characterised by three resistances in series:

1) resistance from the hot liquid bulk to the membrane surface, due to convective transport;

$$
Q_{h}=h_{h} \cdot\left(T_{h}-T_{1}\right)
$$

2) resistance across the membrane, related to convective transport of latent heat with vapour flux $N_{v}$, and conductive transport through the membrane material and the fluid filling the pores $\left(k_{m}\right)$;

$$
Q_{m}=Q_{k}+\lambda_{e v} \cdot N_{v}=k_{m} \cdot\left(T_{1}-T_{2}\right)+C_{T_{m}}^{\prime} \cdot \lambda_{e v} \cdot\left(T_{1}-T_{2}\right)
$$

3) resistance from the membrane surface to the cold bulk, due to convective transport, also linked to temperature polarization effect.

$$
Q_{c}=h_{c} \cdot\left(T_{2}-T_{c}\right)
$$

with

$$
Q_{h}=Q_{m}=Q_{c}
$$

A schematic representation of the mass and heat flux for the membrane distillation process is reported in the following figure 2 (referring to the DCMD configuration):

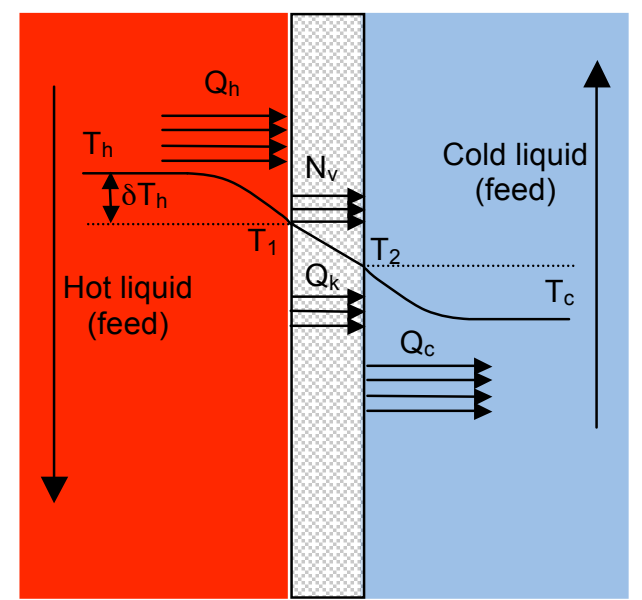

Figure 2 - Transfer Phenomena in Direct Contact Membrane Distillation

As the effective driving force to the vapour flux through the membrane is related to the temperature difference $\left(T_{1}-T_{2}\right)$, while the total available temperature difference is $\left(T_{h}-T_{c}\right)$, the 
T-gradient related to the convective heat flux from the bulk to the membrane, $\delta \mathrm{T}=\mathrm{T}_{\mathrm{h}}-\mathrm{T}_{1}$, can be seen as a driving force loss and is commonly defined as Temperature Polarisation.

Geometry optimization is therefore related to the reduction of such polarization phenomenon, through the promotion of mixing and heat transfer within the channel, at the same time keeping low pressure drops along the channel. 


\section{Models and methods}

In order to reduce computational requirements the modelling approach has been that of studying the fluid flow and temperature fields inside an elementary cell. However, while in the literature many works considered the elementary cell as a single set of crossing filaments $[10,12]$, in this case the cell consisted of a small portion of a spacer filled channel, containing a number (between 5 and 6) of longitudinal and transversal filaments, thus allowing the simulation of the thermo fluid dynamics also among the rows of filaments.

The computational grid was created by Gambit using tetrahedral cells with an average size lower than $0.3 \mathrm{~mm}$. Also in this case a grid dependence analysis was performed indicating that no significant changes were recorded meshing the domain with smaller cells. An image of a portion of a meshed geometry is reported in the following Fig. 3.

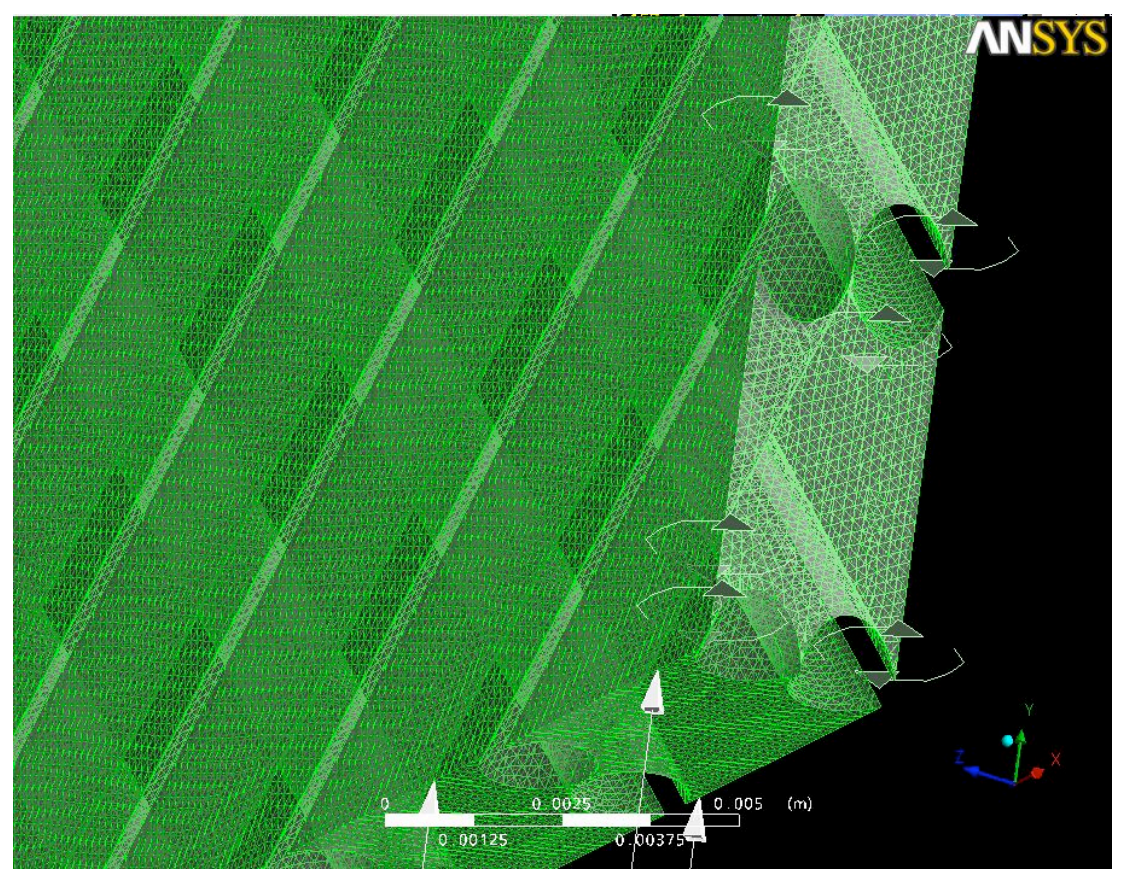

Figure 3 - Detail of a portion of the computational grid for the diamond spacer (type 1)

In order to find the best spacer configuration, several commercial and custom spacer geometries were studied. The main features of the selected geometries are reported in Table 1. 
Table 1. Geometrical features of commercial and custom spacers investigated

\begin{tabular}{|c|c|c|}
\hline Spacer ID & Spacer geometry & Spacer features \\
\hline $\begin{array}{l}\text { Diamond Spacer } \\
\text { type } 1 \text { (custom) }\end{array}$ & & $\begin{array}{l}\text { wire diam: } 1.53 \mathrm{~mm} \text {; } \\
\text { wire angle: } 45^{\circ} \text {; } \\
\text { spacing: } 4.42 \mathrm{~mm} \text {; } \\
\text { thickness: } 3 \mathrm{~mm} \text {; } \\
\text { computational domain dimensions: } \\
31.2 \times 31.2 \mathrm{~mm} \text {; } \\
\text { number of cells: ca } 2 \text { million }\end{array}$ \\
\hline $\begin{array}{l}\text { Diamond Spacer type } \\
2 \text { (commercial, } \\
\text { filaments with } \\
\text { elliptical section) }\end{array}$ & & $\begin{array}{l}\text { wire diam (a): } 2.1 \mathrm{~mm} \text {; } \\
\text { wire diam }(\mathrm{b}): 2.0 \mathrm{~mm} \text {; } \\
\text { wire angle: } 42^{\circ} ; \\
\text { spacing: } 6 \mathrm{~mm} \text {; } \\
\text { thickness: } 4 \mathrm{~mm} \text {; } \\
\text { computational domain dimensions: } \\
32.3 \text { (width) } 35.86 \text { (length) } \mathrm{mm} \text {; } \\
\mathrm{N}^{\circ} \text { of cells: ca } 6.7 \text { million }\end{array}$ \\
\hline $\begin{array}{c}\text { Perpendicular Spacer } \\
\text { (custom) }\end{array}$ & & $\begin{array}{l}\text { wire diam: } 1.53 \mathrm{~mm} \text {; } \\
\text { wire angle: } 0^{\circ} / 90^{\circ} \text {; } \\
\text { spacing: } 5.2 \mathrm{~mm} \text {; } \\
\text { thickness: } 3 \mathrm{~mm} \text {; } \\
\text { computational domain dimensions: } \\
31.2 \times 31.2 \mathrm{~mm} \text {; } \\
\mathrm{N}^{\circ} \text { of cells: ca } 1.5 \text { million }\end{array}$ \\
\hline $\begin{array}{l}\text { Spacer with oblique } \\
\text { wires (commercial) }\end{array}$ & & $\begin{array}{l}\text { wire diam: } 1.53 \mathrm{~mm} \text {; } \\
\text { wire angle: } 0^{\circ} / 45^{\circ} \text {; } \\
\text { longit. spacing: } 5.2 \mathrm{~mm} \text {; } \\
\text { obl. spacing: } 4.42 \mathrm{~mm} \text {; } \\
\text { thickness: } 3 \mathrm{~mm} \text {; } \\
\text { computational domain dimensions: } \\
31.2 \times 31.2 \mathrm{~mm} \text {; } \\
\mathrm{N}^{\circ} \text { of cells: ca } 2.4 \text { million }\end{array}$ \\
\hline
\end{tabular}




\begin{tabular}{|c|c|c|}
\hline $\begin{array}{c}\text { Perpendicular } \\
\text { Trilayer thin (custom) }\end{array}$ & $\operatorname{lam}_{1}$ & $\begin{array}{l}\text { wire diam: } 1.02 \mathrm{~mm} \text {; } \\
\text { wire angle: } 0^{\circ} / 90^{\circ} / 0^{\circ} \text {; } \\
\text { spacing: } 5.2 \mathrm{~mm} \text {; } \\
\text { thickness: } 3 \mathrm{~mm} \text {; } \\
\text { computational domain dimensions: } \\
31.2 \text { x } 31.2 \mathrm{~mm} \text {; } \\
\mathrm{N}^{\circ} \text { of cells: ca } 4.7 \text { million }\end{array}$ \\
\hline $\begin{array}{l}\text { Perpendicular } \\
\text { Trilayer thick } \\
\text { (custom) }\end{array}$ & $=$ & $\begin{array}{l}\text { wire diam: } 1.53 \mathrm{~mm} \text {; } \\
\text { wire angle: } 0^{\circ} / 90^{\circ} / 0^{\circ} \text {; } \\
\text { spacing: } 5.2 \mathrm{~mm} \text {; } \\
\text { thickness: } 4.5 \mathrm{~mm} \text {; } \\
\text { computational domain dimensions: } \\
31.2 \times 31.2 \mathrm{~mm} \text {; } \\
\mathrm{N}^{\circ} \text { of cells: ca } 1.7 \text { million }\end{array}$ \\
\hline $\begin{array}{l}\text { Trilayer with central } \\
\text { oblique wires thin } \\
\text { (custom) }\end{array}$ & & $\begin{array}{l}\text { wire diam: } 1.02 \mathrm{~mm} \text {; } \\
\text { wire angle: } 0^{\circ} / 45^{\circ} / 0^{\circ} \text {; } \\
\text { longit. spacing: } 5.2 \mathrm{~mm} \text {; } \\
\text { obl. spacing: } 4.42 \mathrm{~mm} \text {; } \\
\text { thickness: } 3 \mathrm{~mm} \text {; } \\
\text { computational domain dimensions: } \\
31.2 \times 31.2 \mathrm{~mm} \text {; } \\
\mathrm{N}^{\circ} \text { of cells: ca } 4.6 \text { million }\end{array}$ \\
\hline $\begin{array}{l}\text { Trilayer with central } \\
\text { oblique wires thick } \\
\text { (custom) }\end{array}$ & & $\begin{array}{l}\text { wire diam: } 1.53 \mathrm{~mm} \text {; } \\
\text { wire angle: } 0^{\circ} / 45^{\circ} / 0^{\circ} \text {; } \\
\text { longit. spacing: } 5.2 \mathrm{~mm} \text {; } \\
\text { obl. spacing: } 4.42 \mathrm{~mm} \text {; } \\
\text { thickness: } 4.5 \mathrm{~mm} \text {; } \\
\text { computational domain dimensions: } \\
31.2 \text { x } 31.2 \mathrm{~mm} \text {; } \\
\mathrm{N}^{\circ} \text { of cells: ca } 6 \text { million }\end{array}$ \\
\hline $\begin{array}{c}\text { Quadrilayer with } 2 \\
\text { central oblique wires } \\
\text { layers (custom) }\end{array}$ & & $\begin{array}{l}\text { wire diam: } 0.76 \mathrm{~mm} \text {; } \\
\text { wire angle: } 0^{\circ} / 45^{\circ} /-45^{\circ} / 0^{\circ} \text {; } \\
\text { longit. spacing: } 5.2 \mathrm{~mm} \text {; } \\
\text { obl. spacing: } 4.42 \mathrm{~mm} \text {; } \\
\text { thickness: } 3 \mathrm{~mm} \text {; } \\
\text { computational domain dimensions: } \\
31.2 \text { x } 31.2 \mathrm{~mm} \text {; } \\
\mathrm{N}^{\circ} \text { of cells: ca } 3.7 \text { million }\end{array}$ \\
\hline
\end{tabular}


With reference to the above presented geometries, boundary conditions were set in order to keep the closest relation between imposed and real conditions in these units.

On the lateral surfaces of the domain, a periodic boundary condition was set, assuming that real lateral walls, which normally close the module channel, do not significantly affect the flow field in the central part of the channel (the one here simulated by the elementary cell). It is worth mentioning that such a condition is perfectly suitable for symmetrical spacers, while it can be a wrong simplifying assumption for the case of asymmetrical spacers.

Inlet conditions were imposed by setting the inlet temperature and mass flow rate of the liquid, while at the outlet a pressure boundary condition was imposed with an average relative pressure of 0.0 Pa.

In all simulated cases, flow rates and temperatures were set identical to those typically adopted in real MD spiral wound modules already operating and tested [2]. In particular, inlet mass flow rate was imposed equal to $12.5 \mathrm{~kg} / \mathrm{h}$, and temperature was set to $70^{\circ} \mathrm{C}$.

A single phase (liquid water) system was considered, while evaporation at the membrane surface was indirectly modelled by imposing a heat flux exiting through the membrane. This allowed modelling the heat transfer from the liquid bulk to the membrane surface, thus simulating the temperature polarization effect in the various regions of the computational domain.

In order to estimate and impose the value of heat flux exiting through the membrane, a mass (vapour) flux across the membrane of $5 \mathrm{~kg} / \mathrm{m}^{2} \mathrm{~h}$ has been considered, as it typically occurs in the reference MD modules under the described operating conditions and with a total temperature deriving force $\left(\mathrm{T}_{\mathrm{h}}-\mathrm{T}_{\mathrm{c}}\right)$ of about $10^{\circ} \mathrm{C}$. Such vapour flux is related to the passage of the latent heat, which in turns represents the heat exiting through the membrane due to evaporation. Assuming an average value of the latent heat of evaporation $\lambda_{\mathrm{ev}}=2250 \mathrm{~kJ} / \mathrm{kg}$, the calculated heat flux was of $3.13 \mathrm{~W} / \mathrm{m}^{2}$ (i.e. $11,250 \mathrm{~kJ} / \mathrm{m}^{2} \mathrm{~h}$ ). It is worth noting that this assumption is rather simplifying for two reasons:

- vapour flux can vary significantly with the fluid dynamics conditions inside the channel and in proximity of the membrane;

- the total heat passing through the membrane is related not only to the latent heat due to the vapour passage but also to the heat conduction from the hot to the cold side of the membrane (particularly in the DCMD configuration).

Nevertheless, the above assumption greatly help in defining a common heat output condition for all the different geometries investigated, thus allowing to compare the temperature polarisation achieved in the various cases. 
A no slip condition was imposed on the membrane surfaces and on the filaments of the spacer.

Laminar conditions were simulated. In fact, Reynolds numbers, calculated according to the equation 7 below, were found to be in all cases below 200, and therefore laminar flow can be reasonably assumed [7].

$$
\operatorname{Re}=\frac{v \cdot \rho \cdot D_{e q}}{\mu}
$$

where $v$ is the average liquid velocity within the spacer (across the free section), $\rho$ is the liquid density, $\boldsymbol{\mu}$ is the liquid viscosity and $\boldsymbol{D}_{\boldsymbol{e}}$ is the equivalent diameter defined as:

$$
D_{e q}=4 \cdot \frac{V_{l i q}}{S_{w e t}}
$$

with $V_{\text {liq }}$ equal to the liquid filled volume within the channel, and $\boldsymbol{S}_{\text {wet }}$ the wetted surface of wires and channel walls.

Simulations were performed using ANSYS-CFX11. Laminar steady-state simulations were performed with a total a number of iterations $\mathrm{N}_{\mathrm{i}}$ equal to 5000 . This number has been chosen after a convergence analysis, indicated that good convergence was achieved already after 3000 iterations. 


\section{Results and discussion}

\subsection{Post-process}

Simulation results allowed the collection of detailed information after suitable and effective post-processing of the numerical results.

Velocity, pressure and temperature maps were produced on selected planes highlighted in figure 4. The axes of the reference frame are oriented in such a way that the $\mathrm{x}$-direction is parallel to the width of the channel, the y-direction parallel to the direction of feed flow, and the $\mathrm{z}$-direction perpendicular to the membrane surface. On this ground the selected planes are the following:

- a yellow plane along the xy direction (i.e. parallel to the membrane surface) cutting the first layer of filaments;

- a grey plane parallel to the yellow plane but located at a lower level and cutting the second layer of filaments;

- a transversal red plane along the yz direction perpendicular to the membranes, which can effectively help in understanding any polarisation phenomenon occurring along the $z$ direction perpendicular to the membrane surface.

In the case of 3- and 4-layer spacers a forth plane was also monitored, which cuts the central layer of filaments.

Moreover, in order to quantitatively study polarisation phenomena along the z-direction (i.e. variable from the liquid bulk to the membrane surface), velocity and temperature profiles were also analysed along 9 lines selected in the central part of the domain as reported in figure 5 . 


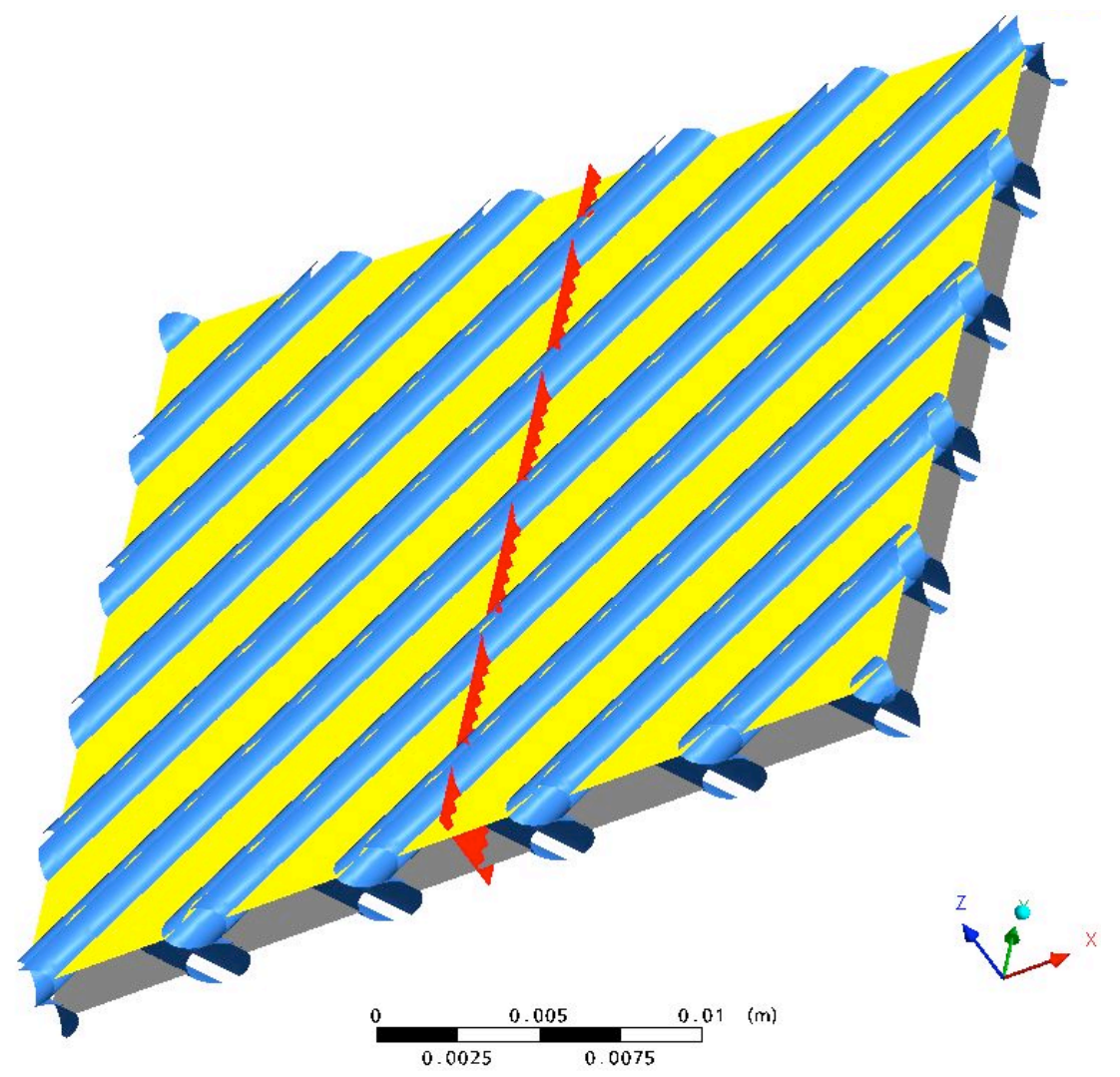

Figure 4 - Planes on which velocity, pressure and temperature maps have been generated

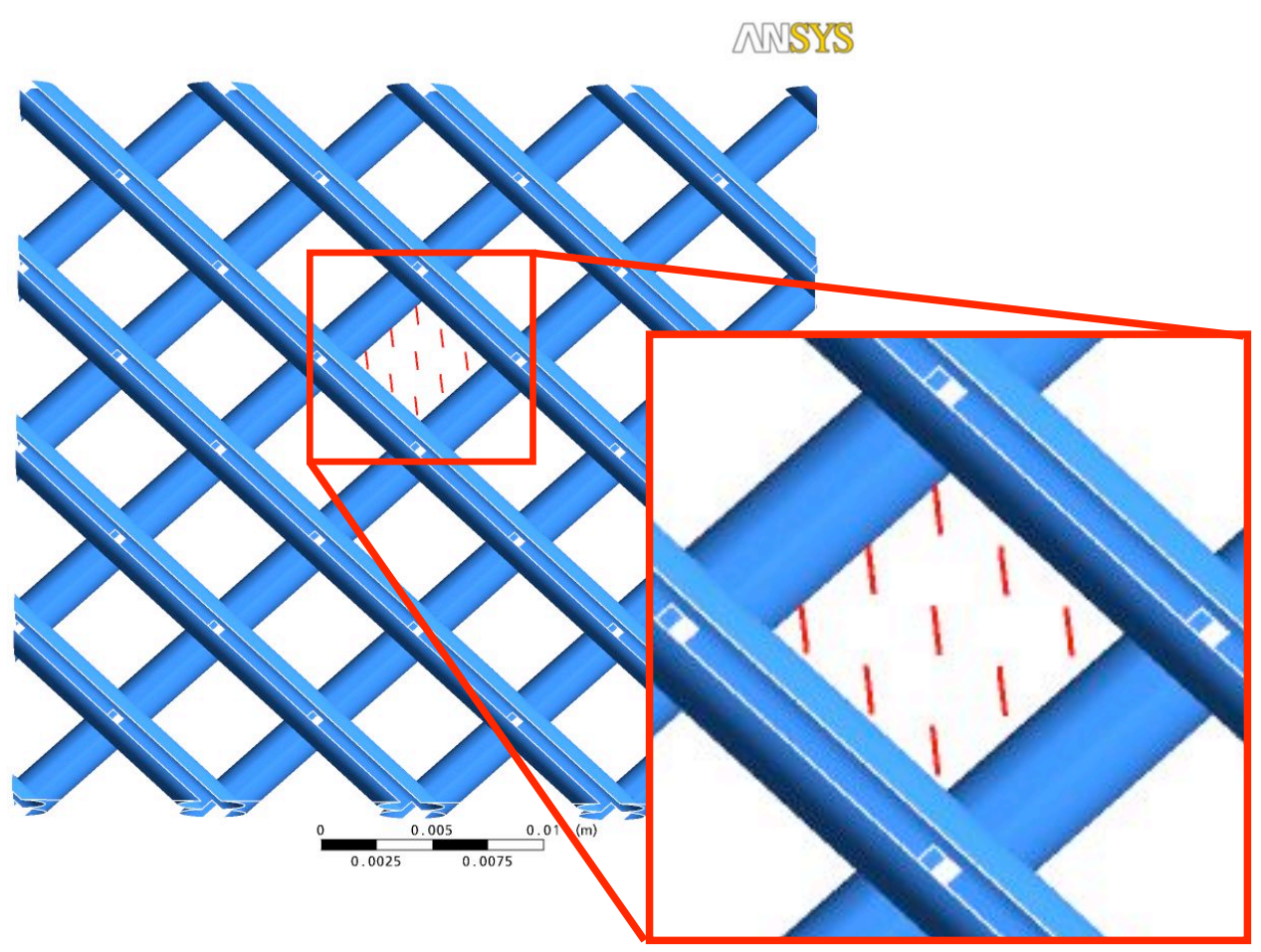

Figure 5 - Lines in the central part of the domain on which Velocity and Temperature profiles have been generated. 

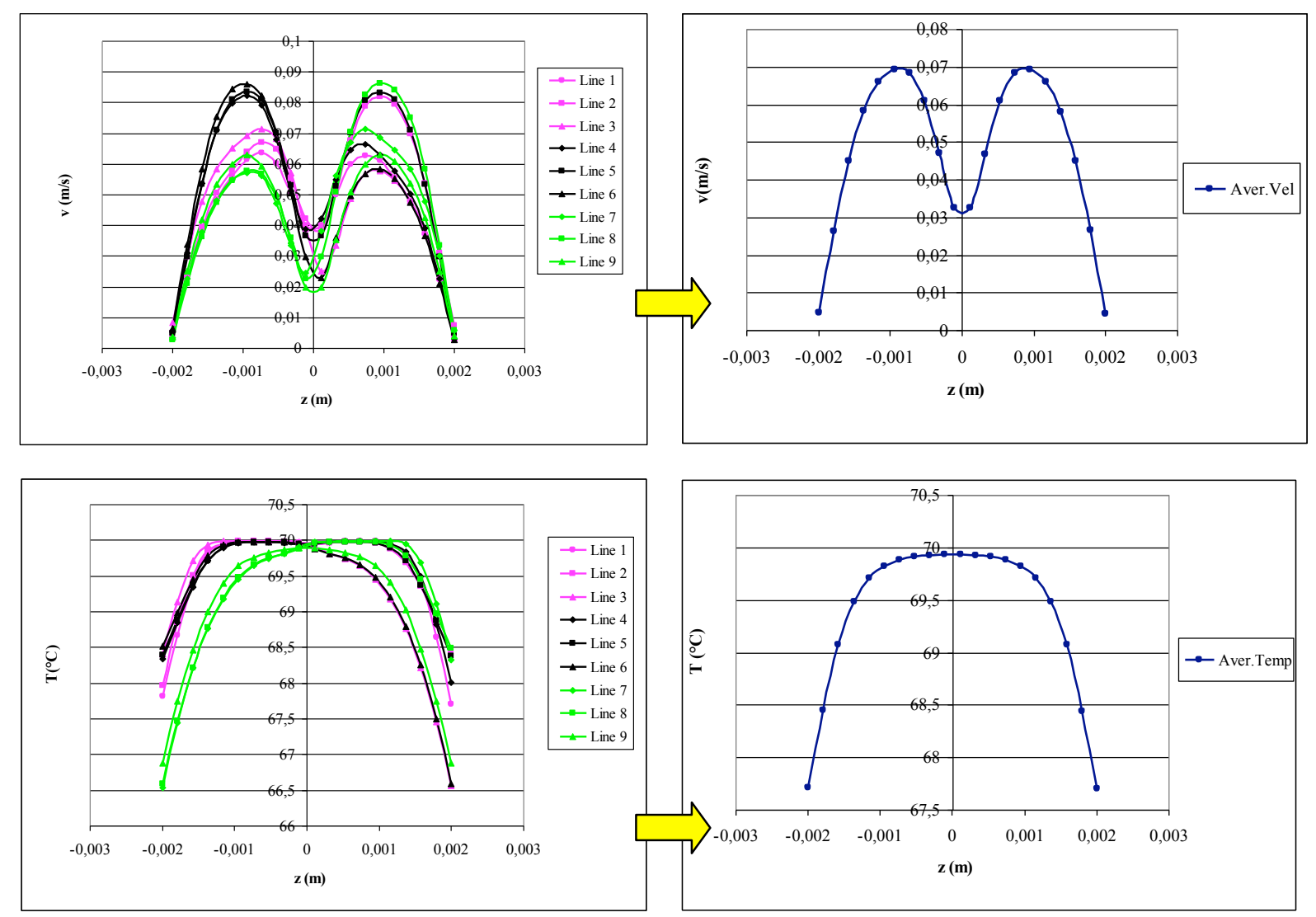

Figure 6 - Typical velocity and temperature profiles along the z-direction in order to obtain average profiles useful for comparison between geometries (referred to the geometry Diamond spacer type 2) .

Finally, to perform an effective comparison between the different geometries, average profiles were computed starting from the nine profiles within the central cell as shown in the right hand side of Fig. 6 (referred to both velocity and temperature profiles of a Diamond spacer type 2).

\subsection{Maps of flow fields and temperature distribution}

The following figure 7 reports colour maps of velocity distributions. Colour maps refer to the planes illustrated in the previous paragraph.

The figure shows how the presence of transversal filaments generally reduces significantly velocities, especially behind such filaments, whereas velocities are found higher between longitudinal filaments. In particular, calm zones with very low or zero velocities are generated behind transversal filaments, in which mixing and transport phenomena are certainly inhibited. Moreover, such behaviour gives rise to a strong asymmetry for asymmetrical 
geometries as in the case of 2-layers with perpendicular and oblique wires. At the same time the increase in thickness of the filaments, which in turn results in enlarging the cross section, reduces velocities in the entire domain.

The behaviour of 3 and 4-layers spacers is actually symmetrical, being this very beneficial for systems in which the membrane is positioned on both sides of the channel as in the present case under investigation.

\begin{tabular}{|c|c|c|c|c|c|}
\hline & I layer & & yz-plane & II Layer & III Layer \\
\hline $\begin{array}{l}\text { Diamond } \\
\text { Spacer type } 1 \\
\text { (custom) }\end{array}$ & $\frac{1}{1} l_{1}$ & 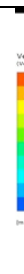 & 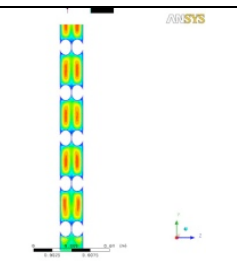 & $\int_{20}$ & \\
\hline $\begin{array}{c}\text { Diamond } \\
\text { Spacer type } 2 \\
\text { (commercial) }\end{array}$ & & & $\tilde{M}$ & & \\
\hline $\begin{array}{l}\text { Perpendicular } \\
\text { Spacer (custom) }\end{array}$ & . & 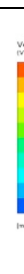 & -1 & 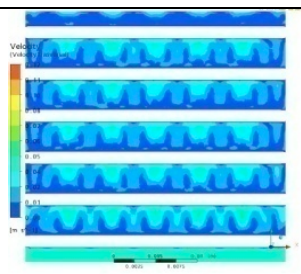 & \\
\hline $\begin{array}{c}\text { Spacer with } \\
\text { oblique wires } \\
\text { (commercial) }\end{array}$ & : & 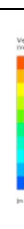 & 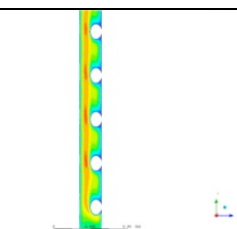 & & \\
\hline $\begin{array}{l}\text { Perpendicular } \\
\text { Trilayer thin } \\
\text { (custom) }\end{array}$ & Ho & 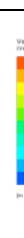 & 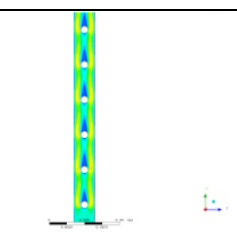 & & \\
\hline $\begin{array}{l}\text { Perpendicular } \\
\text { Trilayer thick } \\
\text { (custom) }\end{array}$ & +4 & 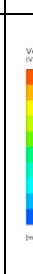 & i. & 17. & 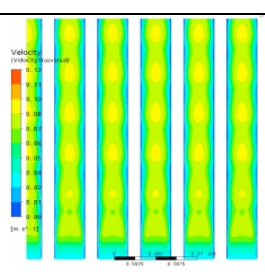 \\
\hline
\end{tabular}




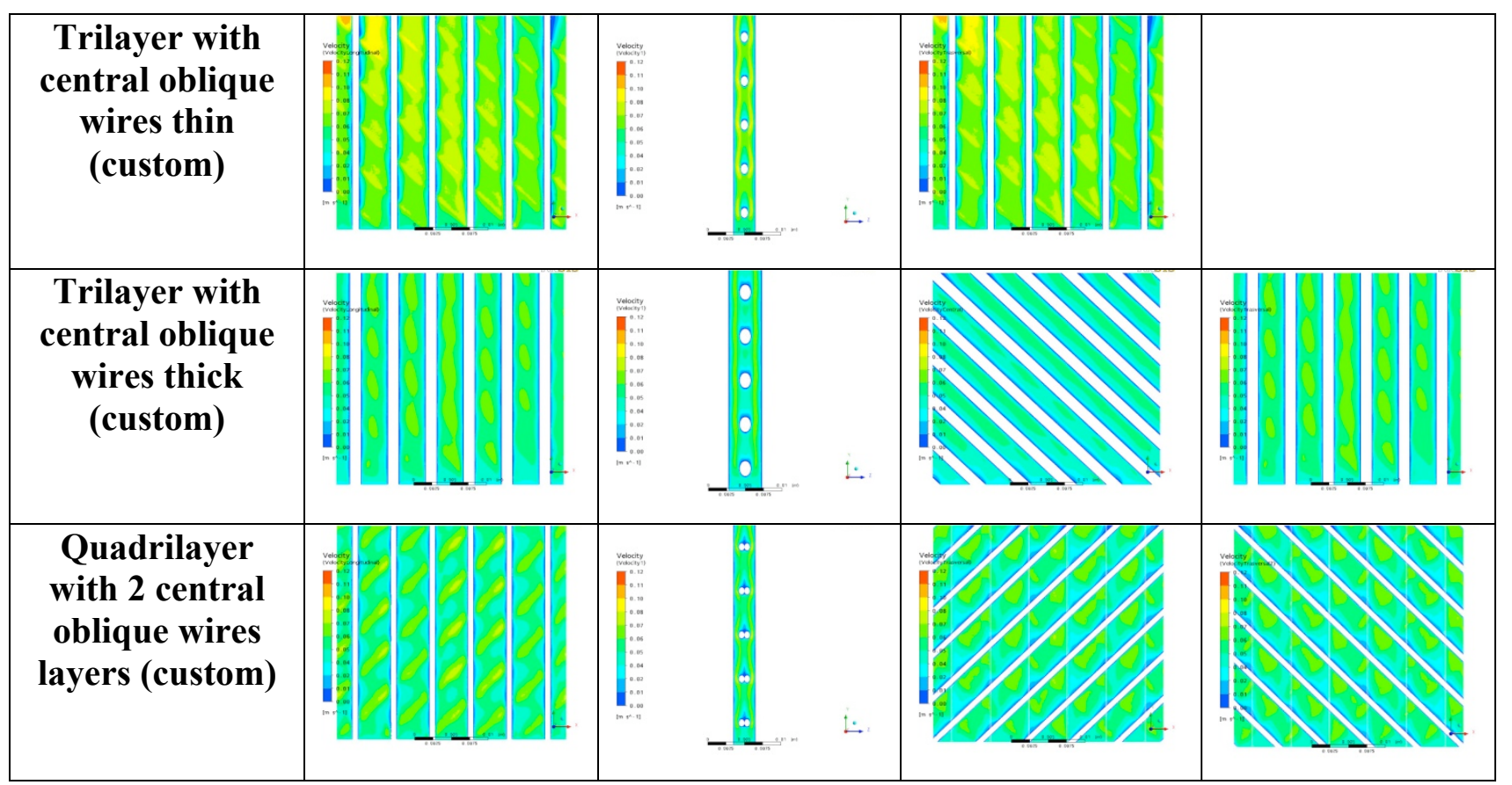

Figure 7 - Velocity fields predicted on the planes highlighted in Fig.4 for all different spacer geometry

Concerning pressure drops along the channel, figure 8 reports the distribution of pressures on the same planes reported in figure 7.

As expected from the previous considerations on velocities, the presence of transversal filaments obstructing the flow, gives rise to higher pressure drops, as can be observed in Fig.7 for the diamond spacer type 1, and perpendicular spacers in general. Of course, lower velocities generated by thicker spacers are coupled with lower pressure drops, which are also relatively low for multi layer spacers in which at least two layers of longitudinal filaments are present.

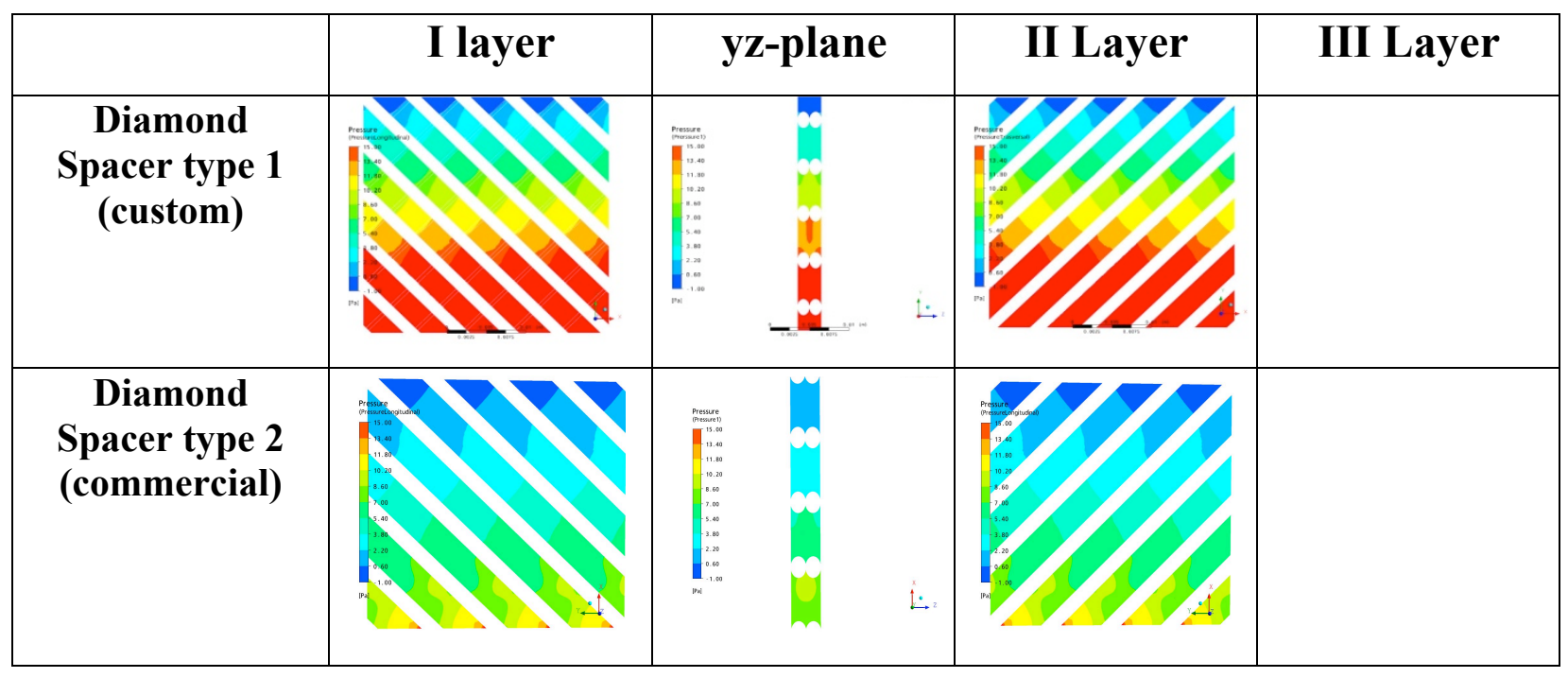




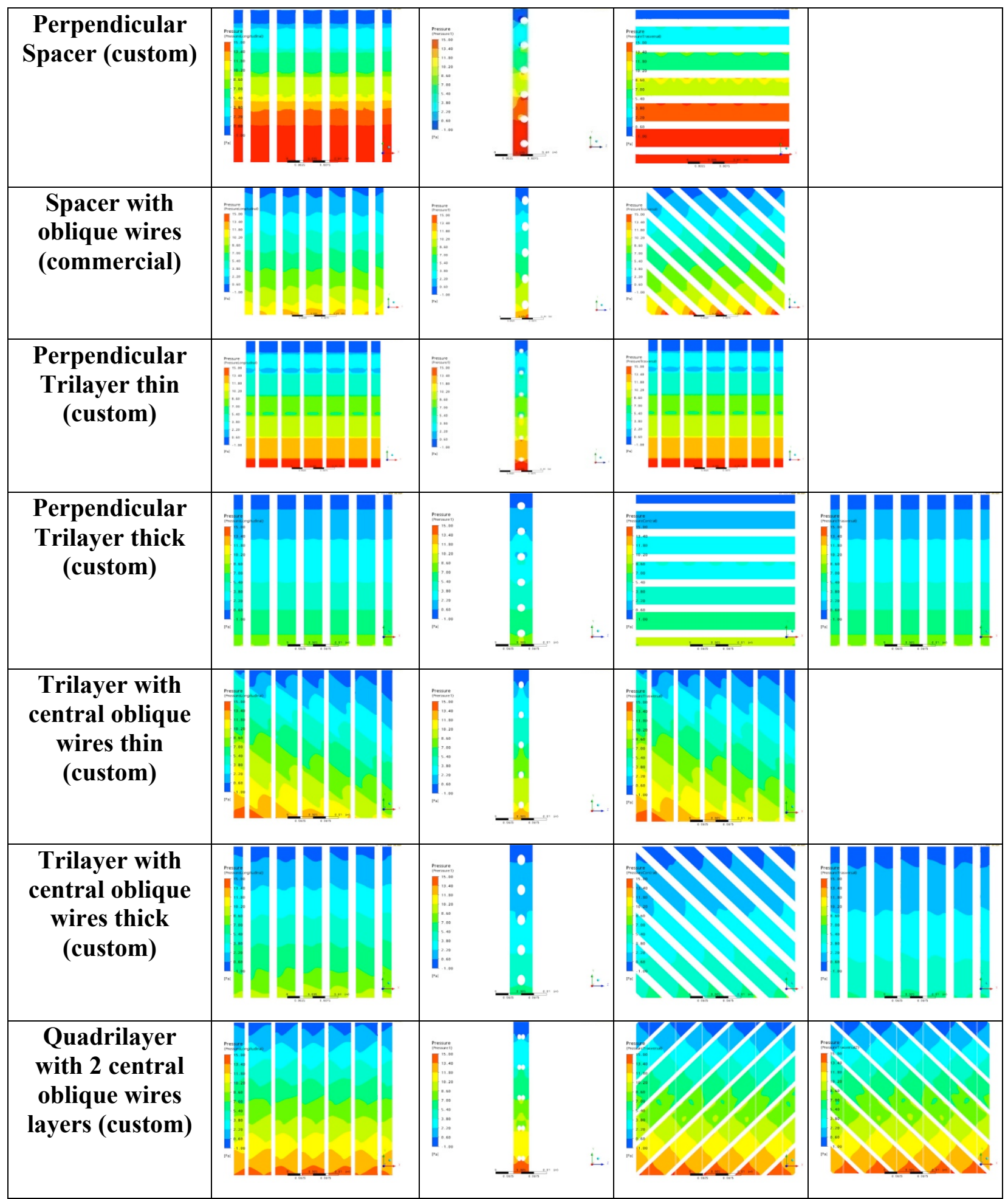

Figure 8 - Pressure distribution predicted on the planes highlighted in Fig. 4 for all different spacer geometry

Figure 9 reports temperature distribution results, with the presence of the exiting heat flux through the membranes self-evident in the reduction of the liquid temperature along the channel. Also the observation of T-distribution in the yz-plane confirms that the presence of transversal filaments obstructing the flow generates calm zone in which mixing is prevented and temperature polarisation seems to increase. At the same time, the use of symmetrical 
multilayer spacers seems to be a good choice given the symmetrical distribution of temperature along z-direction, although the addition of a layer can reduce velocities thus reducing also heat transfer coefficients.

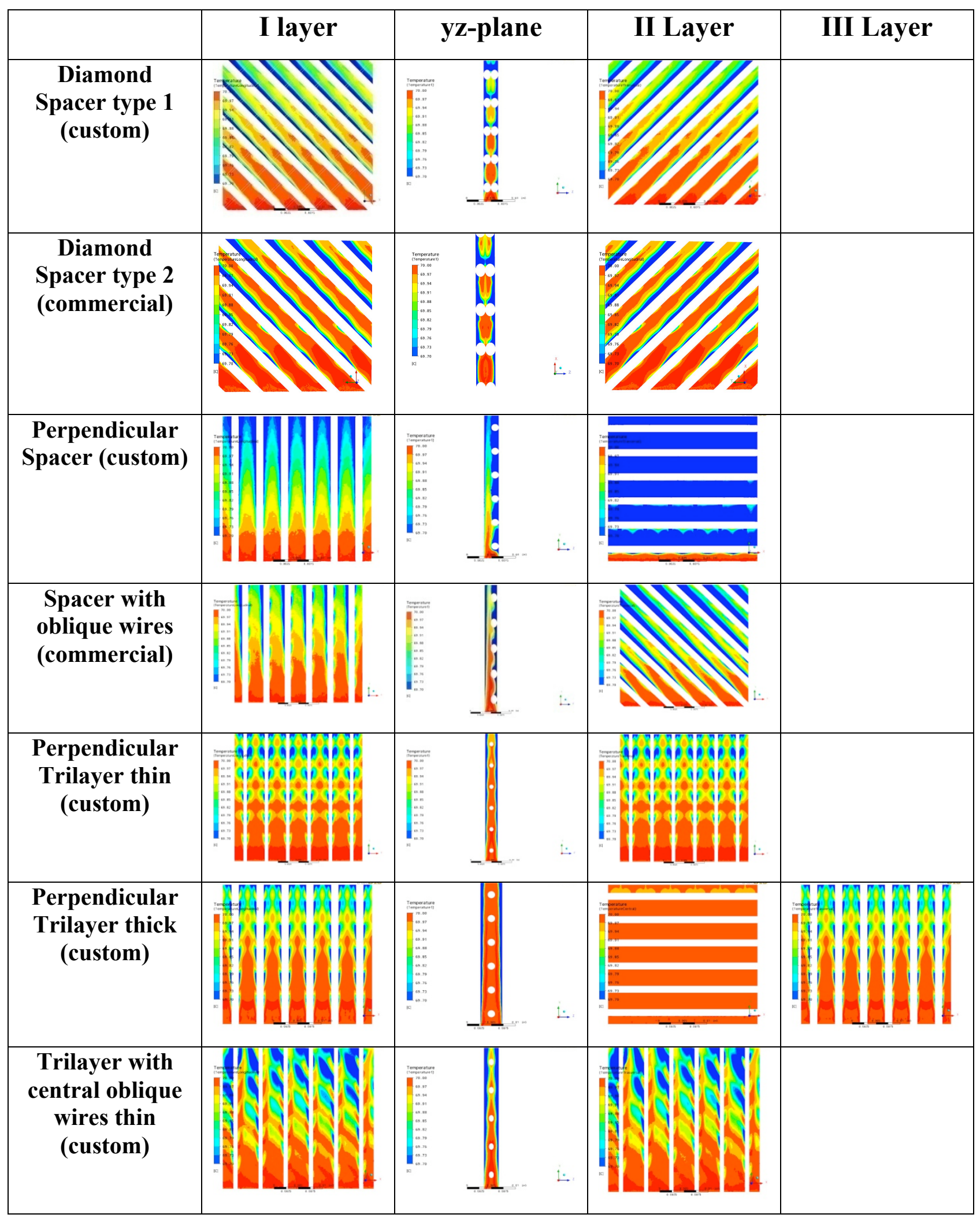




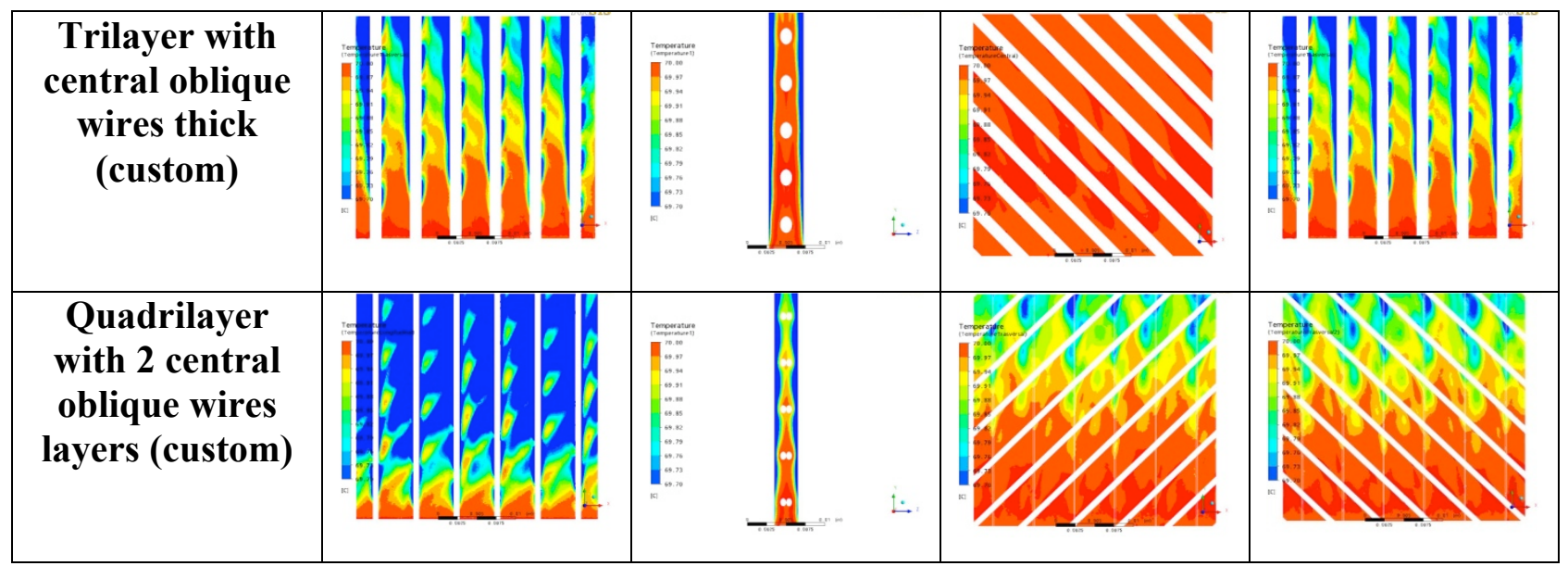

Figure 9 - Temperature distribution on the planes highlighted in Fig.4 for all different spacer geometries.

\subsection{Velocity and temperature distribution along the z-direction}

Figures 10 and 11 report the comparison between different spacer's geometries for velocity and temperature distributions respectively.

Fig.10 confirms the asymmetrical behaviour of perpendicular and oblique spacers, where velocities are lower on the right side (transversal wires) and higher on the left side (longitudinal wires). In diamond spacers a symmetrical behaviour is observed, with lower velocities in the central part of the channel where filaments cross. Moreover lower velocities have been predicted for the spacer diamond type 2, characterised by a slightly larger thickness. On the other side, multilayer spacers present in all cases lower velocities, always perfectly symmetrical and with higher velocities in proximity of the membrane, where longitudinal filaments are present. Of course, also in this case thicker spacers have lower velocities and thinner have higher velocities which are maximum for spacers with a central perpendicular layer. 


\section{2-layers spacers}

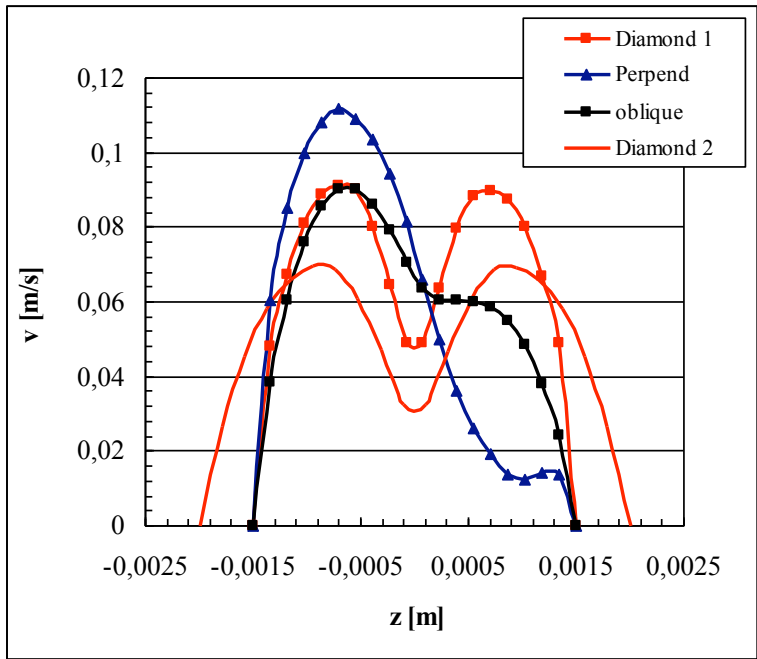

multilayer spacers

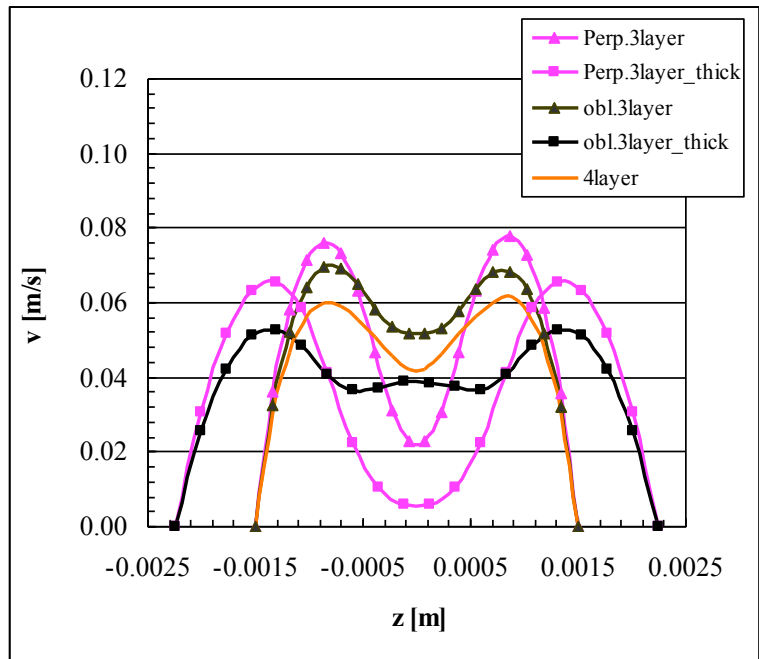

Figure 10 - Comparison of velocity profiles along z-direction for different spacer geometries

\section{2-layers spacers}

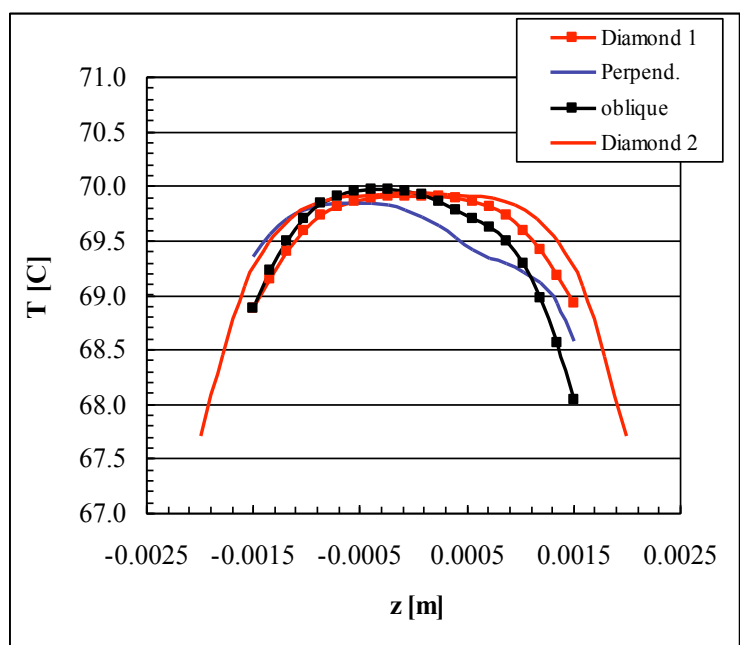

multilayer spacers

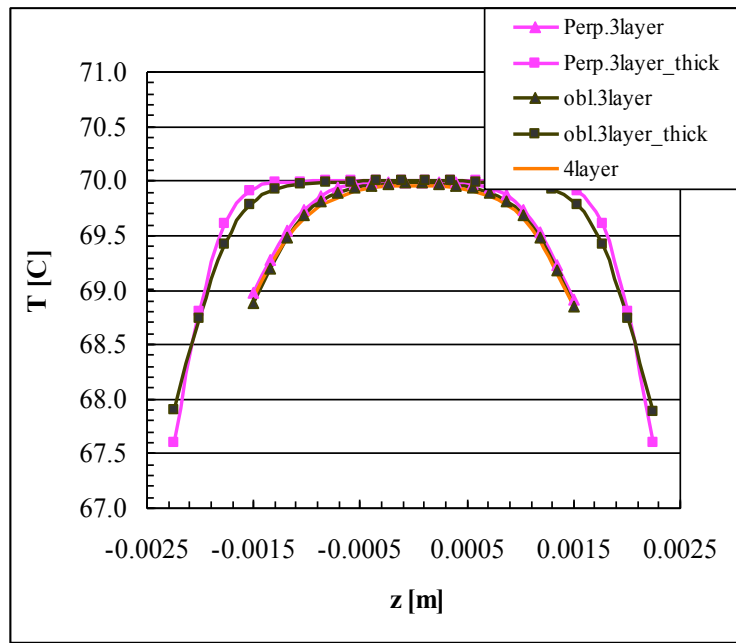

Figure 11 - Comparison of temperature profiles along z-direction for different spacer geometries

Fig.11 reports temperature profiles for the different spacers and it clearly highlights the asymmetrical polarization of temperature for the spacers with perpendicular and oblique layers. In fact, while on the left side polarization is limited to about 0.5 and $1{ }^{\circ} \mathrm{C}$, on the right side it goes up to values of about 1.5 and $2{ }^{\circ} \mathrm{C}$. The thinner diamond spacer has lower polarization than the thicker, likely due to the higher velocities of the former. Concerning multilayer spacers, thicker spacers present the highest T-polarization, whereas thinner spacers present a polarisation of about $1^{\circ} \mathrm{C}$, perfectly symmetrical on the two sides of the channel. 


\subsection{Results summary}

Figure 12 reports an overview of CFD results in terms of average temperature polarisation (average of the left and right side in asymmetrical spacers) versus pressure drop along the channel, for all the different geometries simulated. Notably lower pressure drops are related to quite high temperature polarisation, conversely higher pressure drops are accompanied by less significant polarisation effects. Thin 3-layer and 4-layer spacers have been found to give a good compromise between low $\Delta \mathrm{P}$ and low $\mathrm{T}$-polarisation, especially if compared to the Diamond type 2 and the oblique 2-layer spacers presenting higher T-polarisation with very similar pressure drops.

Such results are in agreement with theoretical expectations that smaller "characteristic lengths" promote heat transfer without significantly increasing pressure losses [14], thus indicating that thinner spacers with filaments mainly parallel to the fluid flow direction are to be preferred.

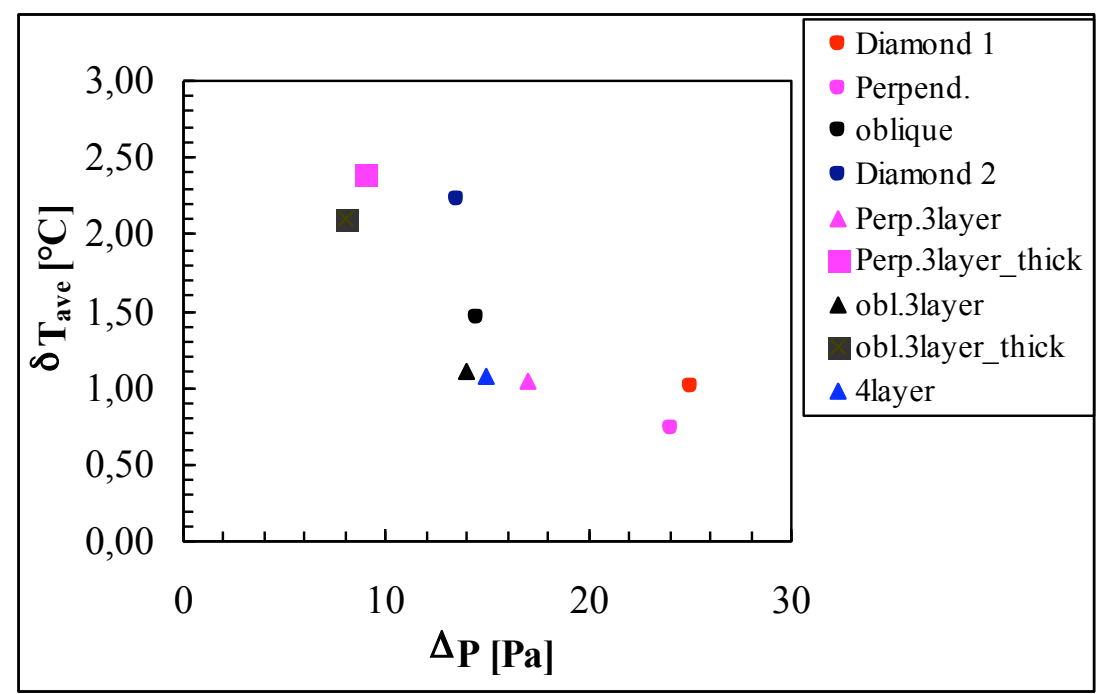

Figure 12 - Mean temperature polarisation versus pressure drop along the channel for all the different geometries simulated. Circles refer to 2-layers spacers; triangle refer to thin 3- and 4-layers spacers; squares refer to thick 3-layers spacers.

\section{Conclusions}

CFD simulations were performed to analyse the fluid flow and temperature fields of several different commercial and custom spacer geometries. Predictions have shown that the presence of longitudinal filaments in proximity of the membrane surface significantly enhances mixing 
and heat transfer, thus contributing to the minimisation of polarisation phenomena. On this basis several custom multilayer geometries have been proposed for which CFD predictions indicate a reduction of T-polarisation from values around $2{ }^{\circ} \mathrm{C}$ (relevant to standard spacers) to values around $1{ }^{\circ} \mathrm{C}$. Moreover, some of them have shown an interestingly good compromise between low $\Delta \mathrm{P}$ and low $\mathrm{T}$-polarisation. Such results are in agreement with theoretical expectations that smaller "characteristic lengths" promote heat transfer without significantly increasing pressure losses, thus indicating that thinner spacers with filaments mainly parallel to the fluid flow direction are to be preferred.

Experimental and modelling activities are still on-going and focused on the validation of CFD results with experiments and on the use of High Performance Computing facilities for the simulation of larger domains of the MD channel.

\section{Acknowledgments}

This work has been carried out with the financial support of the MEDIRAS project within the EU-FP7 research programme (contract number TREN/FP7EN/218938).

Authors acknowledge the precious help of Mr. Antonino Di Miceli for his help in performing CFD simulations.

\section{References}

1. Lawson K. W., Lloyd D. R., Membrane distillation, J. Membr. Sci. 124 (1997), pp. 125.

2. Koschikowski J., Wieghaus M., Rommel M., Solar thermal-driven desalination plants based on membrane distillation, Desalination 156 (2003), pp. 295-304.

3. Da Costa A.R., Fane A.G., Fell C.J.D., Franken A.C.M., Optimal channel spacer design for ultrafiltration, J. Membr. Science 62 (1991), pp. 275-291.

4. Da Costa A.R., Fane A.G., Wiley D.E., Spacer characterization and pressure drop modelling in spacer-filled channels for ultrafiltration, J. Membr. Science 87 (1994), pp. 79-98. 
5. Karode S.K., Kumar A., Flow visualization through spacer filled channel by computational fluid dynamics I. Pressure drop and shear rate calculations for flat sheet geoemtry, J. Membr. Sci., 193 (2001), pp. 69-84.

6. Cao Z., Wiley D. E., Fane A. G., CFD simulation of net-type turbulence promoters in a narrow channel, J. Membrane Sci. (2001).

7. Schwinge J., Wiley D. E., Fletcher D. F., A CFD study of unsteady flow in narrow spacer-filled channels for spiral-wound membrane modules, Desalination (2002).

8. Dendukuri D., Karode S.K., Kumar A., Flow visualization though spacer filled channels by computational fluid dynamics II: improved feed spacer designs, J. Membr. Sci. 249 (2005), pp.41-49.

9. Li F., Meindersma W., de Haan A. B., Reith T., Experimental validation of CFD mass transfer simulations in flat channels with non-woven net spacer, Journal of Membrane Science 232 (2004), pp. 19-30.

10. Ranade V. V., Kumar A., Fluid dynamics of spacer filled rectangular and curvilinear channels, Journal of Membrane science 271 (2006), pp. 1-15.

11. Santos J.L.C., Geraldes V., Verlizarov S., Crespo J.G., Investigation of flow patterns and mass transfer in membrane module channels filled with flow-aligned spacer using computational fluid dynamics (CFD), J. Membr. Sci., 305 (2007), pp. 103-117

12. Koutsou C.P., Yiantsios S.G., Karabelas A.J., Direct numerical simulation of flow in spacer-filled channels: Effect of spacer geometrical characteristics, J. Membr. Sci., 291 (2007), pp.53-69

13. Koutsou C.P., Yiantsios S.G., Karabelas A.J., A numerical and experimental study of mass transfer in spacer-filled channels: Effect of spacer geometrical characteristics and Schmidt number, J. Membr. Sci., 326 (2009), pp. 234-251.

14. Schofield R.W., Fane A.G., Fell C.J.D, Heat and Mass transfer in Membrane Distillation, J. Membr. Sci. 33 (1987), pp. 299-313.

15. Cipollina A., Di Miceli A., Koschikowski J., Micale G., Rizzuti L., CFD simulation of a membrane distillation module channel, Desalination and Water Treatment 6 (2009), pp.177-183. 
16. Xu Z., Pan Y., Yu Y, CFD simulation on membrane distillation of $\mathrm{NaCl}$ solution, Front. Chem. Eng. China 3 (2009), pp. 293-297.

17. Alklaibi A. M., Lior N., Flow modification spacers in membrane distillation (MD) channels, IDA World Congress, Maspalomas, Gran Canaria-Spain, October 21-26, 2007.

18. Martinez-Diez L., Vazquez-Gonzalez M.I., Florido-Diaz F.J., Study of membrane distillation using channel spacers, J. Membr. Sci., 144 (1998), pp.45-56.

19. Srisurichana S., Jiraratananona R., Fane A. G., Mass transfer mechanisms and transport resistances in direct contact membrane distillation process, J. Membr. Sci., 277 (2006), pp. 186-194.

20. Criscuoli A., Carnevale M.C., Drioli E., Evaluation of energy requirements in membrane distillation, Chemical Engineering and Processing 47 (2008), pp. 1098-1105.

21. Cath T. Y., Adams V. D., Childress A. E., Experimental study of desalination using direct contact membrane distillation: a new approach to flux enhancement, J. Membr. Sci. 228 (2004), pp. 5-16. 